Article

\title{
Burnout Precursors in Oncology Nurses: A Preliminary Cross-Sectional Study with a Systemic Organizational Analysis
}

\author{
Loris Bonetti $^{1}{ }^{\circledR}$, Angela Tolotti ${ }^{1}{ }^{\circledR}$, Dario Valcarenghi ${ }^{1}{ }^{\oplus}$, Carla Pedrazzani $^{2}$, \\ Serena Barello ${ }^{3, *} \mathbb{0}$, Greta Ghizzardi ${ }^{4}$, Guendalina Graffigna ${ }^{3}$, Davide Sari ${ }^{1}$ and \\ Monica Bianchi ${ }^{2}$ \\ 1 Nursing Research Centre, Ente Ospedaliero Cantonale and Research and Development Unit of Oncology, \\ Oncology Institute of Southern Switzerland (IOSI), 6500 Bellinzona, Switzerland; loris.bonetti@eoc.ch (L.B.); \\ angela.tolotti@eoc.ch (A.T.); dario.valcarenghi@eoc.ch (D.V.); davide.sari@eoc.ch (D.S.) \\ 2 Department of Business Economics, Health and Social Care, University of Applied Sciences and Arts of \\ Southern Switzerland, 6928 Manno, Switzerland; carla.pedrazzani@supsi.ch (C.P.); \\ monica.bianchi@supsi.ch (M.B.) \\ 3 Department of Psychology, EngageMinds Hub-Consumer \& Health Research Center, Università Cattolica \\ del Sacro Cuore, 20123 Milan, Italy; guendalina.graffigna@unicatt.it \\ 4 Health Professions Research and Developement Unit, IRCCS Policlinico San Donato, San Donato Milanese, \\ 20100 Milan, Italy; greta.ghizza91@gmail.com \\ * Correspondence: serena.barello@unicatt.it; Tel.: +39-02-72343863
}

Received: 25 January 2019; Accepted: 18 February 2019; Published: 26 February 2019

check for updates

\begin{abstract}
Burnout negatively affects nurses' health and performance. Healthcare managers have an ethical duty to create healthy organizations that reduce burnout, especially within critical settings such as oncology. The aim of this study was twofold: (1) to measure the presence of nurses' burnout to formulate organizational strategies to prevent the syndrome onset, and (2) to evaluate the effect of recent organizational changes on the burnout phenomenon. A descriptive, cross-sectional design supported by a systemic organizational analysis was conducted in a Swiss Oncology Institute in 2013. Of 103 nurses working in the Institute, 52 (51.4\%) completed the Burnout Potential Inventory (BPI) questionnaire. Data were analyzed using descriptive statistics and Mann-Whitney and Kruskal-Wallis tests. Burnout risk levels were low to moderate. Only 2 nurses out of the 52 showed moderate burnout risk levels. Inpatient nurses showed a higher risk of burnout than outpatient nurses, particularly due to ambiguity and feelings of powerlessness. Nurses with post-basic education showed a higher risk when considering poor teamwork values and ambiguity in the workplace. Poor middle-management was found to negatively influence worker wellbeing. The working environment set by management resulted in low burnout risk levels. Managers must carefully select middle-management because inappropriate leadership might promote the onset of burnout.
\end{abstract}

Keywords: burnout; oncology nursing; leadership; nurse wellbeing; healthy organizations; sustainable work; patient engagement

\section{Introduction}

Burnout is a prolonged response to chronic emotional and interpersonal stressors on the job, defined by the three dimensions of exhaustion, cynicism, and inefficacy [1]. Burnout is a consequence of ineffectively coping with lasting stressful events within the workplace [2]. Burnout can be triggered by several events, including excessive workload, inadequate social and professional recognition, lack of feedback, and contrast between personal values and organization needs [1,3]. Burnout results in 
non-specific (e.g., fatigue, apathy, and insomnia), physical (e.g., tachycardia, headache, nausea, and muscle pain), and psychological (e.g., guilt, anger, isolation, indifference, cynicism) consequences [4].

When prolonged, this psycho-physical discomfort can present as absenteeism, decreased work performance, and workplace or profession abandonment [3,4]. Maslach [4] identified three main symptoms that characterize burnout that can be measured using the Maslach Burnout Inventory (MBI). These symptoms are: emotional exhaustion, depersonalization, and lack of personal accomplishment [1,2]. The depersonalization dimension was renamed cynicism for the purposes of this study [5].

Recent studies revealed a correlation between burnout and patient outcomes: when burnout decreases, patients' outcomes improve [6,7]. In workplaces where burnout levels are high, there is increased turnover of professionals [8]. Nurses burnout has been studied in several clinical setting, with different results being reported [9-12].

Monsalve-Reyes et al. [9], in a systematic review about burnout in nurses working in primary care, found that emotional exhaustion and low personal accomplishment are very common in this clinical field. They stated that primary care nurses are a group at high risk of burnout. The depersonalization dimension seemed to be higher in emergency nurses than in other clinical fields [10]. In this clinical area, the prevalence of burnout is high and each nurse was positive in at least one dimension of the MBI for burnout syndrome.

Pradas-Hernández et al. [11], in their meta-analysis among burnout in pediatric nurses, found that nurses in this area have moderate-high level of burnout in all the dimensions of MBI. Also in this study, the two dimensions with higher prevalence were emotional exhaustion and lack of professional recognition. In palliative care, the higher prevalence of burnout was found in the personal accomplishment dimension, followed by the emotional exhaustion and depersonalization [12]. Clinical setting and the characteristics of the patients can influence the manifestation of burnout syndrome among nurses, so tailored approaches and prevention strategies are therefore needed.

Oncology nurses and other healthcare professionals that work with cancer patients are at high risk of experiencing burnout due to the grave nature of the patients' conditions. Professionals feel an increase in frustration and a sense of failure, which may result in leaving the oncological field altogether [13-17]. Studies reported workload and the demanding nature of oncology work as main causes of burnout in the oncology setting [18,19]. Identifying those at risk of burnout is an ethical imperative for organizations, especially within the oncology field.

Given the significant repercussions on the quality of care and the health of workers [20], management and organizations should implement strategies to prevent burnout. Recent research emphasized the importance of leadership style: participatory, transformational, and authentic leadership reduces the risk of burnout [16-21]. Arnold et al. [21] reported that transformational leadership is positively related with deep acting and genuine emotion. They also claimed that transformational leaders are those who are want to ensure a positive working environment for their employees. These aspects are related to a higher work satisfaction and commitment, and can prevent burnout syndrome onset. Lewis et al. [22] found that transformational leadership is associated with higher levels of engagement and lower levels of burnout among nurses. Laschinger et al. [23] reported that authentic leadership is significantly correlated with low levels of emotional exhaustion and depersonalization. The same authors [24] found that authentic leadership is has a positive effect on occupational copying self-efficacy, resulting in a lower risk of burnout. In another study with newly-graduated nurses, Laschinger et al. [25] found that civility norms can be influenced by authentic leadership, which promotes a better person-job fit, reduces coworker incivility, prevents burnout, and decreases intention to leave. Similar results were reported by Shanafelt et al. [26] regarding a physician sample. Adequate staffing, professional recognition, autonomy, and decision making power all led to low burnout risk [27].

A recently meta-analytic study about oncology nurse burnout [28], that included studies in which burnout syndrome was evaluated by MBI, reported that the prevalence for each subscale of the MBI is: 
emotional exhaustion 30\% (95\% confidence interval (CI): 26-33\%), depersonalization/cynicism 15\% (95\% CI: 9-23\%), and low professional recognition 35\% (95\% CI: 27-43\%). The dimension of emotional exhaustion is the most related to burnout development in oncology nurses. This result confirms the emotional commitment of oncology nurses that have to deal with patients' deaths, negative outcomes, and bad news [29]. For the same reason, the dimension second-most related to burnout in oncology nurses is low professional recognition; this could be caused by the sense of failure in their role due to the high percentage of death in the patients for which they care [30,31]. Although the overall death rate has decreased in the last years [32], cancer remains one of the principal causes of death in young people; this could lead oncology nurses to feel inadequate in their role [30,31].

According to the literature, personality factors are correlated with burnout syndrome development A study by De Lafluente et al. [33] demonstrated that factors, such as emotional exhaustion and depersonalization, are significantly and positively correlated with neuroticism and negatively correlated with conscientiousness, extraversion, openness, and agreeableness. Personal accomplishment was shown to be negatively correlated with neuroticism, agreeableness, conscientiousness, extraversion, and openness. Finally, emotional exhaustion and depersonalization were demonstrated to be positive correlated with factors, such as anxiety and depression, whereas personal accomplishment was negatively correlated with anxiety and depression [33].

In this study, we wanted to explore external factors that can promote an increased risk of burnout. As we reported before, external factors, such as workload and the nature of oncology patients, can increase the risk of burnout development [18,19,29-32]. Poor management and some kinds of leadership style are also correlated with an increased risk of burnout [21-26].

Knowing external risk factors that promote the development of burnout can be useful for management to implement corrective interventions, and for nurses to understand which aspect can help them prevent the syndrome's development.

In this study, the first objective was to investigate the presence of burnout risk factors at the Oncology Institute of Southern Switzerland (IOSI) by considering inpatient and outpatients departments. The secondary objective was to evaluate the effect of the implemented organizational changes (e.g., adoption of the Primary Nursing model) on the burnout phenomenon.

\section{Materials and Methods}

\subsection{Study Design}

A descriptive cross-sectional design [34] supported by a systemic organizational analysis [35] was conducted to determine the risk of burnout in the Swiss Oncology Institute in 2013, through the administration of the Burnout Potential Inventory (BPI) introduced by Potter [36]. Data collection lasted for two months. This study reports a secondary analysis of a multi-center international study [37] assessing burnout precursors in different clinical contexts.

The Oncology Institute of Southern Switzerland (IOSI)'s nursing management used the opportunity offered by participation in the study to better understand the burnout phenomenon and to plan managerial strategies to prevent the onset of the syndrome. The original and novel contribution of this study is that the research results were used to drive managerial and organizational changes.

The Institute's management aimed to understand dissatisfaction markers of nurses. In the first phase, an organizational analysis was conducted by nursing management to identify possible critical issues that exist, according to systemic organizational analysis. According to this model, we analyzed the organization from the point of view of its basic structure (structural characteristics, resources, and environment), its operational mechanisms (professional autonomy, information, and decision-making processes), and its social processes (relationship among nurses, nurse-manager relationship, and leadership style) [35]. These data were used to identify if burnout precursors existed within the Institute and if preventive strategies were necessary. 


\subsection{Study Sample}

Data were collected using convenience sampling. All nurses (103 in total) working at the [hidden to guarantee a blind review] were included, and no particular exclusion criteria were defined. Therefore, the entire target population was included for the secondary analysis. All participants spoke Italian and were willing and able to answer the questionnaire.

\subsection{Setting}

The IOSI, a comprehensive cancer Centre, is composed of four outpatient departments, two radiology outpatient departments, one hemato-oncology inpatient department, one medical oncology department, one radiotherapy unit, and one palliative care unit. There is also a clinical research unit, which was not considered within this study. The Primary Nursing model has been adopted by this institute.

Welfare and Clinical policies were comparable between departments. A protocol- and procedure-sharing system was adopted by the Institute, and autonomy in management has been encouraged. A high percentage of employees work part-time and on shifts, meaning flexibility in management is necessary. The standard organizational conditions (staffing, skill level, workload, and patient ratio) were better than in other clinical territories. Rare issues, such as absenteeism or high turnover, did not occur during the study.

\subsection{Description of Data Collection Tool}

The BPI [36] is a 48-item questionnaire used to investigate job conditions that can lead to burnout, rather than measuring burnout itself. Hence, this is different from other instruments, such as the MBI [1,2], which is used to investigate the symptomatology. The BPI was adopted since it provides a predictive view on this phenomenon. It was important to determine if there were any burnout precursors in the investigated context, and to highlight these precursors to identify any reduction and/or prevention strategies. Within the questionnaire, professionals indicated how often a specific situation was experienced, using a Likert scale from 1 to 9, where 1 corresponds to "rarely" and 9 to "constantly". The questionnaire was initially validated in Italian by Pompili et al. [38]. Arrigoni et al. [37] re-tested content validity within a panel of experts prior to using Potter's Italian version for their study purpose.

The survey consisted of 12 areas, as shown in Table 1.

Table 1. Burnout Potential Inventory (BPI) areas [24].

\begin{tabular}{ll}
\hline \multicolumn{2}{l}{ Burnout Dimensions } \\
\hline 1. & Powerless \\
\hline 2. & No Information \\
\hline 3. & Conflict \\
\hline 4. & Poor Team Work \\
\hline 5. & Overload \\
\hline 6. & Boredom \\
\hline 7. & Poor Feedback \\
\hline 8. & Punishment \\
\hline 9. & Alienation \\
\hline 10. & Ambiguity \\
\hline 11. & Unrewarding \\
\hline 12. & Values Conflict \\
\hline
\end{tabular}


Three levels of burnout risk can be identified by summing the answers resulted from each item: (1) From 48 to 168: low burnout risk, (2) from 169 to 312: moderate burnout risk, and (3) from 313 to 432: high burnout risk.

The questionnaire included participants' demographic variables, such as: age, sex, marital status, physical illness, psychological illness, work place (inpatients or outpatients department), education, years of experience as a nurse, full-time or part-time job (with the percentage of worked hours, i.e., $50 \%$, $70 \%, 80 \%, 90 \%$, or $100 \%)$. All these data were self-reported.

\subsection{Data Collection Methods}

A printed BPI questionnaire was delivered in a sealed envelope with a letter explaining the research objectives and the instructions for the survey, signed by the Nurse Director. An additional sheet, containing questions about age, sex, marital status, working experience in years, qualifications, presence of somatic and psychological illnesses, and full or part time employment, was attached.

\subsection{Statistical Analysis}

All data were entered into an Excel worksheet (2013 version, Microsoft, USA). Statistical analysis was completed using SPSS ${ }^{\circledR}$ software, 22.0 version (IBM, Chicago, IL, USA). Nominal variables were analyzed using frequency and percentage. Continuous variables were analyzed using mean and standard deviation. Ordinal variables were analyzed by using median and quartile. According to the cut-off established by the BPI [36], respondents were classified into low, moderate, or high risk groups for developing burnout. The data were not normally distributed, as determined by the Shapiro-Wilk test. Thus, burnout risk levels were investigated through the non-parametric Mann-Whitney Test comparing the two groups. The non-parametric Kruskal-Wallis Test (KW) was used when more than two groups were compared. Analysis was performed two groups at a time. The Bonferroni correction of the $p$ value was adopted when significant differences were detected by the KW Test. A $p<0.05$ was considered statistically significant [39].

\subsection{Ethical Considerations}

The study was approved from the Institutional Review Board of the University of Pavia in 2013 (int/23/10/2013). The letter to participants reported the adherence to the ethics guidelines, and data confidentiality was ensured. Each participant signed a written consent. All questionnaires were alphanumerically coded to guarantee anonymity. Confidential data, such as name or date of birth, were not collected.

\section{Results}

\subsection{Organizational Analysis}

We analysed the organization from the point of view of its basic structure, its operational mechanisms, and its social processes [35]. Workplace structure was in line with the need of the workers. Comfort, cleanliness, lighting, and functionality requirements in work environments (e.g., changing rooms, canteens, meeting spaces, and toilets) were suitable for the number of professionals working. Innovation within the organization was rated high, as well as a willingness to adapt to changing market demands. Decentralization of operational mechanisms and process management was completed via delegation to each unit. There was favorable autonomy in processes management. All the middle management attended an internal training course on leadership, which showed that a participative and empowering leadership style is place. 


\subsection{Focus on Primary Nursing Model}

The Primary Nursing model has been active since 2007 in the [hidden to guarantee a blind review]. In this model, each patient has a referral nurse who holistically takes care of them way, coordinating the care and those involved. The nurse thus becomes a key reference point for the patient [40].

Primary nursing allows a patient-centered care; this provides the opportunity to be closer to the patients and their caregivers, establishes a more effective therapeutic relationship, and improves the ability to monitor condition evolution and intercept any complications [40].

Greater autonomy and decision-making power, to feel closer to the patient and the possibility to provide holistic and person-centered care, probably improved nurses' work satisfaction, contributing to preventing the onset of burnout [41].

\subsection{Survey}

Of 103 questionnaires, $52(51.4 \%)$ of the returned questionnaires were fit for analysis. The sample consisted of 41 (78.8\%) women with an average age of 47 years. Most participants were married; there were no widows or widowers. Reported psychological illness was low $(n=4 ; 7.7 \%)$, whereas the percentage of physical illness was higher $(n=25 ; 13 \%)$. The sample was equally distributed for workplace (outpatient, inpatient) and education (registered nurse/bachelor degree or post-education certificate). Respondents all fell into the range of working from $70 \%$ to $100 \%$ full time. The sample consisted of nurses with experience (median $=20$ years), as shown in Table 2.

Table 2. Characteristics of the participants $(N=52)$.

\begin{tabular}{cc}
\hline Characteristics & Mean \pm SD \\
\hline Age & $46.7 \pm 9.5$ \\
\hline Sex & $N(\%)$ \\
Male & $11(21.2)$ \\
Female & $41(78.8)$ \\
\hline Marital status & $N(\%)$ \\
Single & $12(23.1)$ \\
Married & $22(42.3)$ \\
Divorced & $11(21.1)$ \\
Other (i.e., cohabitant) & $7(13.5)$ \\
Widow /Widower & $(0)$ \\
\hline Psychological illnes & $N(\%)$ \\
Yes & $4(7.7)$ \\
No & $48(92.3)$ \\
\hline Physical illnes & $N(\%)$ \\
Yes & $13(25)$ \\
No & $39(75)$ \\
\hline Workplace & $N(\%)$ \\
Outpatients & $23(44.2)$ \\
Inpatients & $28(55.8)$ \\
\hline Education & $N(\%)$ \\
Percentage of worked hours (\%) & $22(42.3)$ \\
\hline Post-education & $30(57.7)$ \\
\hline Registered nurse or bachelor degree & Me[Q1;Q3] \\
& $20[11 ; 27]$ \\
\hline
\end{tabular}

$\S \mathrm{Me}=$ Median; $\mathrm{Q} 1$ = first quartile; $\mathrm{Q} 3$ = third quartile. 
Only two nurses (3.8\%) presented with moderate burnout risk, and none presented high burnout risk. The BPI items identified conflict, lack of teamwork, overload, and lack of information obtained with the highest scores $(\geq 6.5)$. Scarcity of feedback, ambiguity, and lack of power followed, as seen in Table 3 .

Table 3. BPI total score and subscales median and percentiles $(N=52)$.

\begin{tabular}{|c|c|c|c|c|}
\hline BPI Subscale & Mean $( \pm$ SD) & $\mathrm{Me}^{\S}$ & Q1 $^{\mathrm{s}}$ & Q3 \\
\hline Powerless & $7.56(2.33)$ & 6 & 4.25 & 8.75 \\
\hline No Information & $7.34(3.19)$ & 6.5 & 5 & 8.75 \\
\hline Conflict & $10.69(4.33)$ & 10 & 7 & 13.75 \\
\hline Poor Team Work & $9.08(3.44)$ & 9 & 6 & 12 \\
\hline Overload & $10.73(5.33)$ & 9 & 6.25 & 12.75 \\
\hline Boredom & $6(2.89)$ & 5 & 4 & 7 \\
\hline Poor Feedback & $7.52(4.54)$ & 6 & 4 & 8 \\
\hline Punishment & $5.21(1.83)$ & 4 & 4 & 6 \\
\hline Alienation & $6.91(3.78)$ & 5 & 4 & 7.75 \\
\hline Ambiguity & $8.3(3.46)$ & 6 & 4 & 9.75 \\
\hline Unrewarding & $6.73(4.28)$ & 5 & 4 & 7.75 \\
\hline Values Conflict & $6.39(2.57)$ & 5 & 4 & 8 \\
\hline Total score & $92.30(26.52)$ & 84.5 & 67 & 105.5 \\
\hline
\end{tabular}

The comparison showed no significant differences in total score or in items regarding sex, marital status, years of work experience, presence of somatic or psychological illnesses, or percentage of work. However, significant differences emerged with regard to lack of power and ambiguity in the working environment (outpatient or inpatient), a lack of teamwork, ambiguity, and conflicts of value, which were dependent on education (registered nurse/bachelor degree or post-education certificate), as shown in Table 4.

Table 4. BPI Comparison of outpatients vs. inpatients and registered nurse/bachelor degree vs. post-secondary education.

\begin{tabular}{|c|c|c|c|c|c|c|}
\hline & $\begin{array}{l}\text { Outpatients } \\
\text { Me[Q1;Q3] }\end{array}$ & $\begin{array}{l}\text { Inpatients } \\
\text { Me[Q1;Q3] }\end{array}$ & $p$ Value $^{\wedge}$ & $\begin{array}{c}\text { Bachelor } \\
\text { Degree } \\
\text { Me[Q1;Q3] }\end{array}$ & $\begin{array}{l}\text { Post-Education } \\
\text { Me[Q1;Q3] }\end{array}$ & $p$ Value \\
\hline Powerless & $5[4 ; 8]$ & $7[6 ; 10]$ & 0.021 * & $6[4 ; 8.25]$ & $6[4.75 ; 9.25]$ & 0.72 \\
\hline No Information & $6[4 ; 10]$ & $7[5 ; 8]$ & 0.83 & $7[4 ; 10.25]$ & $6[5 ; 8.25]$ & 0.76 \\
\hline Conflict & $9[6.5 ; 13]$ & $10[7 ; 14]$ & 0.64 & $9[5.75 ; 11.25]$ & $11[8 ; 15.25]$ & 0.06 \\
\hline Poor Team Work & $8[5.5 ; 13.5]$ & $10[6 ; 12]$ & 0.9 & $7[4.75 ; 10]$ & $10[6.75 ; 15]$ & $0.014 *$ \\
\hline Overload & $9[5.5 ; 13]$ & $9[7 ; 12]$ & 0.6 & $8[4.75 ; 11]$ & $10.5[7 ; 16]$ & 0.055 \\
\hline Boredom & $5[4 ; 7]$ & $4[4 ; 7]$ & 0.5 & $4[4 ; 5.5]$ & $6[4 ; 8.5]$ & 0.134 \\
\hline Poor Feedback & $5[4 ; 9]$ & $6[4 ; 8]$ & 0.7 & $5[4 ; 8]$ & $6[4 ; 10.25]$ & 0.12 \\
\hline Punishment & $4[4 ; 6.5]$ & $4[4 ; 6]$ & 0.9 & $4[4 ; 8]$ & $4[4 ; 6]$ & 0.62 \\
\hline Alienation & $4[4 ; 7.5]$ & $6[4 ; 8]$ & 0.22 & $4.5[4 ; 7]$ & $5[4 ; 9.25]$ & 0.35 \\
\hline Ambiguity & $4[4 ; 7.5]$ & $7[5 ; 11]$ & $0.011 *$ & $5[4 ; 8.25]$ & $6.5[4 ; 10$ & $0.011 *$ \\
\hline Unrewarding & $4[4 ; 7.5]$ & $5[4 ; 8]$ & 0.4 & $5[4 ; 7]$ & $5[4 ; 8]$ & 0.27 \\
\hline Values Conflict & $5[4 ; 8]$ & $5[4 ; 8]$ & 0.5 & $4[4 ; 6.25]$ & $5[6 ; 9]$ & $0.002 *$ \\
\hline Total score & $83[55.5 ; 100]$ & $89[72 ; 117]$ & 0.4 & $72.5[55.5 ; 102.2$ & $92[73 ; 129.5]$ & 0.054 \\
\hline
\end{tabular}

Since the two professionals at risk for burnout both worked in the same unit, a comparison between this unit and all others was conducted. There were significant differences seen for the 
following characteristics: lack of information, poor team work, overload, poor feedback and punishment. Table 5 indicates the poor results of the unit for the two professionals at risk of burnout.

Table 5. Comparison of clinical environment in which nurses had moderate risk vs. the ones in which they had low risk.

\begin{tabular}{|c|c|c|c|}
\hline & $\begin{array}{c}\text { Environment } \\
\text { Where Nurse Showed } \\
\text { Moderate Risk }(N=6) \\
\text { Me[Q1;Q3] } \S\end{array}$ & $\begin{array}{c}\text { Environment } \\
\text { Where Nurse Showed } \\
\text { Low Risk }(N=48) \\
\text { Me[Q1;Q3] }\end{array}$ & $p$ Value ${ }^{\wedge}$ \\
\hline No Information & $12[8.75 ; 16.25]$ & $6[5 ; 8]$ & 0.02 \\
\hline Poor Team Work & $13.5[8 ; 17.75]$ & $8.5[5.75 ; 11.25]$ & 0.033 \\
\hline Overload & $16[10 ; 20]$ & $9[6 ; 11.25]$ & 0.026 \\
\hline Poor Feedback & $14[5.75 ; 25.75]$ & $5[4 ; 8]$ & 0.01 \\
\hline Punishment & $7[5.5 ; 10.5]$ & $4[4 ; 6]$ & 0.09 \\
\hline Total score & $131[88 ; 185.5]$ & $80[65.75 ; 101.75]$ & 0.015 \\
\hline
\end{tabular}

${ }^{\S} \mathrm{Me}=$ Median; $\mathrm{Q} 1$ = first quartile; $\mathrm{Q} 3$ = third quartile; ${ }^{\wedge}$ Mann Whitney test.

\section{Discussion}

In this study, the first aim was to investigate the presence of burnout risk and its precursors at the [hidden to guarantee a blind review] to provide information for planning managerial strategies to prevent onset of the syndrome. The oncological field is at an increased risk of burnout [13-17]. It is important for management to understand the risk of burnout order to adopt strategies to prevent employees from leaving this clinical specialty $[17,20]$.

We found that the majority of participants were at a low risk for burnout. Only two nurses $(3.8 \%)$ in a group of 52 had a moderate risk of burnout, and no nurses exhibited high risk.

These results are different from what the literature reports in oncology clinical setting, where burnout prevalence is usually high. Cañadas-De la Fuente et al. [28], in their recent meta-analytic study, reported that the prevalence was 30\% for emotional exhaustion, $15 \%$ for depersonalization, and $35 \%$ for low personal accomplishment. In a Chinese study [42] conducted in oncological settings in the personal accomplishment MBI dimension, the percentage reported was higher than that reported by De la Fuente et al. [28], with a prevalence of $47.28 \%$. In Iran, Teleghani et al. [43] found a negative correlation between empathy and burnout. In Portugal, Cumbe et al. [44] found that the dimension emotional exhaustion was correlated with lower levels of adaptive coping and less expertise in oncology setting. Also, a greater amount of hours worked per week was associated with a higher emotional exhaustion. Otherwise, personal accomplishment was associated with adaptive coping strategies. In this study, the reported burnout prevalence was higher than our finding.

The low risk of burnout in our study is in line with the organizational analysis from which no particular difficulties have arisen. The evaluation of the [hidden to guarantee a blind review], management found a suitable work environment when considering the hard organizational characteristics (e.g., staff level, skill mix, workload, and part-time work) and the soft (e.g., training, professional development). This result is supported by the literature [45], which expressed that the management is fundamental to the prevention of burnout in the job environment. Management should adopt a leadership style to improve and maintain this positive work environment [46].

The secondary aim of this study was to evaluate the effect of organizational changes (e.g., adoption of Primary Nursing model) on the burnout phenomenon. The Primary Nursing model allows professionals to adopt a holistic approach, have greater professional autonomy, and receive better recognition. These elements are related to low levels of burnout, as demonstrated in the literature [27].

In the study by Dal Molin et al. [47], all patients' relevant clinical outcomes improved with the Primary Nursing implementation. In the same study, both nurses and patients were satisfied with this 
model of care, which allowed the creation of a more effective patient-to-nurse relationship than other work organization models.

In [hidden to guarantee a blind review], the highest BPI dimensions were those related to role and relational aspects, such as conflicts, lack of teamwork, ambiguity, lack of a powerful leadership, and work overload. The results were comparable to those in the study conducted by Arrigoni et al. [37], where critical issues emerged in the dimensions of lack of teamwork and work overload.

In Arrigoni et al. [37], there were no high-risk employees, but the percentage of those subjected to moderate risk was higher $(13.8 \%)$ than in this study $(3.8 \%)$. The differences may, in part, be due the different context of the study. The perception of overload between the two contexts, which differ from one another both in organization and resources, could be further explored. Besides work overload, difficulties in interpersonal relations (i.e., lack of teamwork, ambiguity) and low consideration (i.e., feeling powerless) received the highest scores. Although not at high levels, these elements are important for nursing management to consider to identify strategies for improving the work environment [48].

Managers play a key role in the defense of the professional identity of nursing role and in promoting positive outcomes for patients, as demonstrated in the literature $[6,7,49]$. In contrast to the literature [50,51], we found no significant correlations with sex, length of service, or marital status. This result could be due to the fact that the risk levels of burnout were quite uniform and low, and large variation was not observed. Nurses who work in inpatient departments suffer more in the BPI dimensions than those in the outpatient departments. These nurses specifically reported feeling less powerful and experiencing greater role ambiguity. This may be partly because in an outpatient department, nurses are more autonomous and follow the same patients for longer periods of time. This likely bolsters the perception of greater decision-making power and autonomy, while reducing the ambiguity of the role.

Those with post-graduate training are exposed to higher levels of risk when considering lack of teamwork and value conflicts as a higher education can also create higher job expectations, which are not always met. Considering that the two cases of moderate burnout risk were two nurses working in the same ward, a deeper analysis was conducted. We revealed a significant difference in various dimensions, including lack of information, poor teamwork, poor feedback, punishment, and overload. The dimensions that were most critical were related to management and organizational problems, specific to the leadership of this particular unit. The leadership style can greatly influence the risk of burnout, and a participatory and genuine leadership style is related to low levels of burnout. The opposite occurs with an authoritarian and "laissez-faire" leadership style [15-20]. This was confirmed by a recent study conducted in Sweden, which showed that a nurse's reason for leaving the oncological field was the leadership style [11]. An intervention resulting from this survey was supervision and coaching by the Nurse Director of the Head Nurse.

\subsection{Limitations}

This study has some limitations. The data collected and presented represent a small sample, even though it is a multi-center study. Therefore, widespread conclusions cannot be drawn. Although the sample was small, it is important to underline that the sample represented more than $50 \%$ of the overall nursing staff in this institute, and therefore possibly provides an overview of burnout risk factors in our context.

Our results are different than what is reported in literature, in which burnout is usually quite prevalent in oncology settings. For this reason, our results could be informative for the scientific community because they provide an example on what works in maintaining a low level of burnout risk in oncology setting. The usefulness of this study is that it provides an example of how management can use research as an instrument for analysis and organizational change. 


\subsection{Implications for Practice}

The [hidden to guarantee a blind review] is a working environment where the organizational conditions resulted in workers with a low risk of burnout. Certain managerial aspects encourage a positive work atmosphere, as confirmed by the literature, including adequate resources, appropriate staffing, the use of the Primary Nursing model, flexibility in assessment, attention to training, and professional development. Even under ideal organizational conditions, the risk of burnout could still be present due to role and relational problems. The leadership style of nursing middle management can considerably impact relational issues, as noted in this study. Middle managers should therefore be chosen wisely. It is important to support this role in addition to quickly identifying any signs of dysfunction and rectifying immediately. Finally, implementing strategies to avoid professionals' burnout is an ethical and pragmatic priority, and this aspect has been correlated with practitioners' ability to promote patient engagement, which ultimately leads to better clinical outcomes $[52,53]$.

Nurses can adopt certain strategies in order to avoid burnout in their work. Alexander et al. [54] reported in their pilot randomized trial that, in the experimental group, after an eight-week yoga intervention, self-care strategies significantly improved and emotional exhaustion and depersonalization decreased. In their systematic review, Gillan et al. [55] outlined three principal strategies to promote nurses psychological well-being at work: foster connections within the team, develop behaviors that assist in controlling or limiting the intensity of stress by training and courses, and provide the opportunity to process emotion and create learning from experiences. In a Korean study [56], the author reported the positive effect of group rational emotive behavior therapy on the nurse job stress and burnout; this strategy also improved job satisfaction and organizational commitment and reduced the turnover intention. In an integrative review, van der Riet et al. [57] reported that mindfulness can be an effective strategy to prevent burnout and workplace stress among nurses and nursing students. Finally, Ercolani et al. [58,59] suggested that professional training about coping and communication skills could be useful in burnout prevention in a palliative care ward.

\section{Conclusions}

We investigated the risk of burnout within the oncology setting and reflected on organizational aspects that might facilitate or predict nurse burnout. Low levels of burnout are an indicator of a positive work environment that is peaceful and cooperative, ultimately leading to more effective patient engagement. Only two participants showed a moderate level of risk (within the same department), which was higher than the rest of the sample. This led to a focus on the nursing leadership style and management strategies. The BPI is a useful tool for identifying the risk factors of burnout. This tool can be applied by management to investigate the presence of professionals' burnout precursors, and thus respond accordingly with appropriate strategies.

Author Contributions: For research articles with several authors, a short paragraph specifying their individual contributions must be provided. The following statements should be used "conceptualization, D.V., L.B., and T.A.; methodology, L.B., P.C., S.B.; software, L.B.; validation, D.V., L.B., and T.A.; formal analysis, L.B.; investigation, L.B., B.M.; data curation, L.B.; writing-original draft preparation, L.B., D.V.; writing-review and editing, S.B., G.G. (Guendalina Graffigna), G.G. (Ghizzardi Greta); visualization, L.B.; supervision, D.V., S.D.; project administration, D.V., S.D., B.M.

Funding: This research received no external funding.

Conflicts of Interest: The authors declare no conflict of interest.

\section{References}

1. Maslach, C.; Schaufeli, W.B.; Leiter, M.P. Job Burnout. Annu. Rev. Psychol. 2001, 52, 397-422. [CrossRef] [PubMed]

2. Maslach, C.; Jackson, S.E. The measurement of experienced burnout. J. Organ. Behav. 1981, 2, 99-113. [CrossRef] 
3. Borgogni, L.; Consiglio, C. Job burnout: Evoluzione di un costrutto. Giornale Italiano di Psicologia 2005, 32, 23-60.

4. Marsala, E. Il burnout degli infermieri analisi critica e ricerca bibliografica della letteratura. Inferm. Oggi 2009, 19, 20-29.

5. Schaufeli, W.B.; Leiter, M.P.; Maslach, C. Burnout: 35 years of research and practice. Career Dev. Int. 2009, 14, 204-220. [CrossRef]

6. Van Bogaert, P.; Kowalski, C.; Weeks, S.M.; Van Heusden, D.; Clarke, S.P. The relationship between nurse practice environment, nurse work characteristics, burnout and job outcome and quality of nursing care: A cross-sectional survey. Int. J. Nurs. Stud. 2013, 50, 1667-1677. [CrossRef] [PubMed]

7. Van Bogaert, P.; Van heusden, D.; Somers, A.; Tegenbos, M.; Wouters, K.; Van der Straeten, J.; Van Aken, P.; Havens, D.S. The Productive Ward program ${ }^{\mathrm{TM}}$ : A longitudinal multilevel study of nurse perceived practice environment, burnout, and nurse-reported quality of care and job outcomes. J. Nurs. Adm. 2014, 44, 452-461. [CrossRef] [PubMed]

8. Shoorideh, F.A.; Ashktorab, T.; Yaghmaei, F.; Alavi Majd, H. Relationship between ICU nurses' moral distress with burnout and anticipated turnover. Nurs. Ethics 2015, 22, 64-76. [CrossRef] [PubMed]

9. Monsalve-Reyes, C.S.; San Luis-Costas, C.; Gómez-Urquiza, J.L.; Albendín-García, L.; Aguayo, R.; Cañadas-De la Fuente, G.A. Burnout syndrome and its prevalence in primary care nursing: A systematic review and meta-analysis. BMC Fam. Pract. 2018, 19, 59. [CrossRef] [PubMed]

10. Gómez-Urquiza, J.L.; De la Fuente-Solana, E.I.; Albendín-García, L.; Vargas-Pecino, C.; Ortega-Campos, E.M.; Cañadas-De la Fuente, G.A. Prevalence of Burnout Syndrome in Emergency Nurses: A Meta-Analysis. Crit. Care Nurse 2017, 37, e1-e9. [CrossRef] [PubMed]

11. Pradas-Hernández, L.; Ariza, T.; Gómez-Urquiza, J.L.; Albendín-García, L.; De la Fuente, E.I.; Cañadas-De la Fuente, G.A. Prevalence of burnout in paediatric nurses: A systematic review and meta-analysis. PLoS ONE 2018, 13, e0195039. [CrossRef] [PubMed]

12. Parola, V.; Coelho, A.; Cardoso, D.; Sandgren, A.; Apóstolo, J. Prevalence of burnout in health professionals working in palliative care: A systematic review. JBI Database Syst. Rev. Implement. Rep. 2017, 15, 1905-1933. [CrossRef] [PubMed]

13. Gómez-Urquiza, J.L.; Aneas-López, A.B.; Fuente-Solana, E.I.; Albendín-García, L.; Díaz-Rodríguez, L.; Fuente, G.A. Prevalence, Risk Factors, and Levels of Burnout Among Oncology Nurses: A Systematic Review. Oncol. Nurs. Forum 2016, 43, E104-E120. [CrossRef] [PubMed]

14. Hlubocky, F.J.; Back, A.L.; Shanafelt, T.D. Addressing Burnout in Oncology: Why Cancer Care Clinicians Are at Risk, What Individuals Can Do, and How Organizations Can Respond. Am. Soc. Clin. Oncol. Educ. Book 2016, 35, 271-279. [CrossRef] [PubMed]

15. Lagerlund, M.; Sharp, L.; Lindqvist, R.; Runesdotter, S.; Tishelman, C. Intention to leave the workplace among nurses working with cancer patients in acute care hospitals in Sweden. Eur. J. Oncol. Nurs. 2015, 19, 629-637. [CrossRef] [PubMed]

16. Shang, J.; Friese, C.R.; Wu, E.; Aiken, L.H. Nursing practice environment and outcomes for oncology nursing. Cancer Nurs. 2013, 36, 206-212. [CrossRef] [PubMed]

17. Toh, S.G.; Ang, E.; Devi, M.K. Systematic review on the relationship between the nursing shortage and job satisfaction, stress and burnout levels among nurses in oncology/haematology settings. Int. J. Evid. Based Healthc. 2012, 10, 126-141. [CrossRef] [PubMed]

18. Sherman, A.C.; Edwards, D.; Simonton, S.; Mehta, P. Caregiver stress and burnout in an oncology unit. Palliat. Support. Care 2006, 4, 65-80. [CrossRef] [PubMed]

19. Kleiner, S.; Wallace, J.E. Oncologist burnout and compassion fatigue: Investigating time pressure at work as a predictor and the mediating role of work-family conflict. BMC Health Serv. Res. 2017, 17, 639. [CrossRef] [PubMed]

20. Harrison, K.L.; Dzeng, E.; Ritchie, C.S.; Shanafelt, T.D.; Kamal, A.H.; Bull, J.H.; Tilburt, J.C.; Swetz, K.M. Addressing palliative care clinician burnout in organizations: A workforce necessity, an ethical imperative. J. Pain Symptom Manag. 2017, 53, 1091-1096. [CrossRef] [PubMed]

21. Arnold, K.A.; Connelly, C.E.; Walsh, M.M.; Ginis, K.A. Leadership styles, emotion regulation, and burnout. J. Occup. Health Psychol. 2015, 20, 481-490. [CrossRef] [PubMed]

22. Lewis, H.S.; Cunningham, C.J. Linking Nurse Leadership and Work Characteristics to Nurse Burnout and Engagement. Nurs. Res. 2016, 65, 13-23. [CrossRef] [PubMed] 
23. Laschinger, H.K.; Wong, C.A.; Grau, A.L. Authentic leadership, empowerment and burnout: A comparison in new graduates and experienced nurses. J. Nurs. Manag. 2013, 21, 541-552. [CrossRef] [PubMed]

24. Laschinger, H.K.; Borgogni, L.; Consiglio, C.; Read, E. The effects of authentic leadership, six areas of worklife, and occupational coping self-efficacy on new graduate nurses' burnout and mental health: A cross-sectional study. Int. J. Nurs. Stud. 2015, 52, 1080-1089. [CrossRef] [PubMed]

25. Laschinger, H.K.; Read, E.A. The Effect of Authentic Leadership, Person-Job Fit, and Civility Norms on New Graduate Nurses' Experiences of Coworker Incivility and Burnout. J. Nurs. Adm. 2016, 46, 574-580. [CrossRef] [PubMed]

26. Shanafelt, T.D.; Gorringe, G.; Menaker, R.; Storz, K.A.; Reeves, D.; Buskirk, S.J.; Sloan, J.A.; Swensen, S.J. Impact of organizational leadership on physician burnout and satisfaction. Mayo Clin. Proc. 2015, 90, 432-440. [CrossRef] [PubMed]

27. Nowrouzi, B.; Lightfoot, N.; Larivière, M.; Carter, L.; Rukholm, E.; Schinke, R.; Belanger-Gardner, D. Occupational Stress Management and Burnout Interventions in Nursing and Their Implications for Healthy Work Environments: A Literature Review. Workplace Health Saf. 2015, 63, 308-315. [CrossRef] [PubMed]

28. Cañadas-De la Fuente, G.A.; Gómez-Urquiza, J.L.; Ortega-Campos, E.M.; Cañadas, G.R.; Albendín-García, L.; De la Fuente-Solana, E.I. Prevalence of burnout syndrome in oncology nursing: A meta-analytic study. Psychooncology 2018, 27, 1426-1433. [CrossRef] [PubMed]

29. Medland, J.; Howard-Ruben, J.; Whitaker, E. Fostering psychosocial wellness in oncology nurses: Addressing burnout and social support in the workplace. Oncol. Nurs. Forum 2004, 31, 47-54. [CrossRef] [PubMed]

30. Peters, L.; Cant, R.; Payne, S.; O'Connor, M.; McDermott, F.; Hood, K.; Morphet, J.; Shimoinaba, K. How death anxiety impacts nurses caring for patients at the end of life: A review of literature. Open Nurs. J. 2013, 7, 14-21. [CrossRef] [PubMed]

31. Barbour, L.C. Exploring oncology nurses grief: A self-study. Asia Pac. J. Oncol. Nurs. 2016, 3, $233-240$. [CrossRef] [PubMed]

32. Hashim, D.; Boffetta, P.; La Vecchia, C.; Rota, M.; Bertuccio, P.; Malvezzi, M.; Negri, E. The global decrease in cancer mortality: Trends and disparities. Ann. Oncol. 2016, 27, 926-933. [CrossRef] [PubMed]

33. De la Fuente-Solana, E.I.; Gómez-Urquiza, J.L.; Cañadas, G.R.; Albendín-García, L.; Ortega-Campos, E.; Cañadas-De la Fuente, G.A. Burnout and its relationship with personality factors in oncology nurses. Eur. J. Oncol. Nurs. 2017, 30, 91-96. [CrossRef] [PubMed]

34. Hallberg, I.R. Survey. In Nursing Research: Designs and Methods; Watson, R., McKenna, H., Cowman, S., Keady, J., Eds.; Churchill Livingstone Elsevier: Edinburgh, UK, 2008; pp. 179-188.

35. Vaccani, R. Riprogettare la Sanità. Modelli di Analisi e Sviluppo; Carrocci Faber: Rome, Italy, 2012.

36. Potter, B. Overcoming Job Burnout: How to Renew Enthusiasm for Work; Ronin Publishing: Berkeley, CA, USA, 2005.

37. Arrigoni, C.; Caruso, R.; Campanella, F.; Berzolari, F.G.; Miazza, D.; Pelissero, G. Investigating burnout situations, nurses' stress perception and effect of a post-graduate education program in health care organizations of northern Italy: A multicenter study. Giornale Italiano di Medicina del Lavoro ed Ergonomia 2015, 37, 39-45. [PubMed]

38. Pompili, M.; Rinaldi, G.; Lester, D.; Girardi, P.; Ruberto, A.; Tatarelli, R. Hopelessness and suicide risk emerge in psychiatric nurses suffering from burn-out and using specific defense mechanisms. Arch. Psychiatr. Nurs. 2006, 20, 135-143. [CrossRef] [PubMed]

39. Polit, D.; Tatano Beck, C. Nursing Research: Generating and Assessing Evidence for Nursing Practice, 10th ed.; Wolters Kluwer Health/Lippincott Williams \& Wilkins: Philadelphia, PA, USA, 2017.

40. Ruch, S. Primary Nursing: A Call for Clarity, Empowerment, and Accountability. Creat. Nurs. 2018, 24, 66-67. [CrossRef] [PubMed]

41. Nadeau, K.; Pinner, K.; Murphy, K.; Belderson, K.M. Perceptions of a Primary Nursing Care Model in a Pediatric Hematology/Oncology Unit. J. Pediatr. Oncol. Nurs. 2017, 34, 28-34. [CrossRef] [PubMed]

42. Shen, A.; Wang, Y.; Qiang, W. A Multicenter Investigation of Caring Behaviors and Burnout among Oncology Nurses in China. Cancer Nurs. 2018. [CrossRef] [PubMed]

43. Taleghani, F.; Ashouri, E.; Saburi, M. Empathy, Burnout, Demographic Variables and their Relationships in Oncology Nurses. Iran. J. Nurs. Midwifery Res. 2017, 22, 41-45. [CrossRef] [PubMed] 
44. Cumbe, V.F.J.; Pala, A.N.; Palha, A.J.P.; Gaio, A.R.P.; Esteves, M.F.; de Jesus Mari, J.; Wainberg, M. Burnout syndrome and coping strategies in Portuguese oncology health care providers. Rev. Psiquiatr. Clin. 2017, 44, 122-126. [CrossRef] [PubMed]

45. Gountas, S.; Gountas, J.; Soutar, G.; Mavondo, F. Delivering good service: Personal resources, job satisfaction and nurses' 'customer' (patient) orientation. J. Adv. Nurs. 2014, 70, 1553-1563. [CrossRef] [PubMed]

46. Guo, Y.F.; Luo, Y.H.; Lam, L.; Cross, W.; Plummer, V.; Zhang, J.P. Burnout and its association with resilience in nurses: A cross-sectional study. J. Clin. Nurs. 2018, 27, 441-449. [CrossRef] [PubMed]

47. Dal Molin, A.; Gatta, C.; Boggio Gilot, C.; Ferrua, R.; Cena, T.; Manthey, M.; Croso, A. The impact of primary nursing care pattern: Results from a before-after study. J. Clin. Nurs. 2018, 27, 1094-1102. [CrossRef] [PubMed]

48. Segura-Camacho, A.; García-Orozco, J.J.; Topa, G. Sustainable and Healthy Organizations Promote Employee Well-Being: The Moderating Role of Selection, Optimization, and Compensation Strategies. Sustainability 2018, 10, 3411. [CrossRef]

49. Lozza, E.; Castiglioni, C. Tax climate in the national press: A new tool in tax behaviour research. J. Soc. Political Psychol. 2018, 6, 401-419. [CrossRef]

50. Cañadas-De la Fuente, G.A.; Vargas, C.; San Luis, C.; García, I.; Cañadas, G.R.; De la Fuente, E.I. Risk factors and prevalence of burnout syndrome in the nursing profession. Int. J. Nurs. Stud. 2015, 52, 240-249. [CrossRef] [PubMed]

51. Caruso, R.; Miazza, D.; Gigli Berzolari, F.; Grugnetti, A.M.; Lichosik, D.; Arrigoni, C. Gender differences among cancer nurses' stress perception and coping: An Italian single centre observational study. Giornale Italiano di Medicina del Lavoro ed Ergonomia 2017, 39, 93-99. [PubMed]

52. Barello, S.; Graffigna, G.; Pitacco, G.; Mislej, M.; Cortale, M.; Provenzi, L. An educational intervention to train professional nurses in promoting patient engagement: A pilot feasibility study. Front. Psychol. 2017, 7, 2020. [CrossRef] [PubMed]

53. Barello, S.; Graffigna, G. Tools and Technologies for Patients and Caregivers Engagement: A Qualitative Analysis of Health Professionals' Attitudes and Day-to-Day Practice. In International Symposium on Pervasive Computing Paradigms for Mental Health; Springer: Cham, Switzerland, 2018; pp. 139-149.

54. Alexander, G.K.; Rollins, K.; Walker, D.; Wong, L.; Pennings, J. Yoga for Self-Care and Burnout Prevention Among Nurses. Workplace Health Saf. 2015, 63, 462-470. [CrossRef] [PubMed]

55. Gillman, L.; Adams, J.; Kovac, R.; Kilcullen, A.; House, A.; Doyle, C. Strategies to promote coping and resilience in oncology and palliative care nurses caring for adult patients with malignancy: A comprehensive systematic review. JBI Database Syst. Rev. Implement. Rep. 2015, 13, 131-204. [CrossRef]

56. Kim, H.L.; Yoon, S.H. Effects of Group Rational Emotive Behavior Therapy on the Nurses' Job Stress, Burnout, Job Satisfaction, Organizational Commitment and Turnover Intention. J. Korean Acad. Nurs. 2018, 48, 432-442. [CrossRef] [PubMed]

57. Van der Riet, P.; Levett-Jones, T.; Aquino-Russell, C. The effectiveness of mindfulness meditation for nurses and nursing students: An integrated literature review. Nurse Educ. Today 2018, 65, 201-211. [CrossRef] [PubMed]

58. Graffigna, G.; Barello, S. Spotlight on the Patient Health Engagement model (PHE model): A psychosocial theory to understand people's meaningful engagement in their own health care. Patient Prefer. Adherence 2018, 12, 1261. [CrossRef] [PubMed]

59. Ercolani, G.; Varani, S.; Peghetti, B.; Franchini, L.; Malerba, M.B.; Messana R1 Sichi, V.; Pannuti, R.; Pannuti, F. Burnout in Home Palliative Care: What Is the Role of Coping Strategies? J. Palliat. Care 2019. [CrossRef] [PubMed]

(C) 2019 by the authors. Licensee MDPI, Basel, Switzerland. This article is an open access article distributed under the terms and conditions of the Creative Commons Attribution (CC BY) license (http:/ / creativecommons.org/licenses/by/4.0/). 